\title{
ПЕРЕСЕЧЕНИЕ ИНТЕРПРЕТАЦИИ И КОГНИТИВНЫХ СПОСОБНОСТЕЙ
}

\begin{abstract}
Аннотация. В статье рассматриваются вопросы пересечения и взаимного влияния интерпретации и когнитивных способностей. Обращение к когнитивной проблематике предполагает изучение проблем познания и организации знания и информации, которые обеспечивают адекватную и эффрективную ориентацию и активность человека в мире. Их успешность во многом опосредована имеющимися у субъекта знаниями и возможностью с ними оперировать - понимать и действовать, используя наличный опыт. В процессе интерпретации ключевое значение также имеет использование этих аспектов. В статье определяется место и участие интерпретации в реализации основных когнитивных способностей. Познание является сложным, затрагивающим различные аспекты, предметом исследования. Это предполагает использование в качестве основного междисциплинарного подхода, привлечения материала по психологии, когнитивным дисциплинам и философии. При обращении к рассмотрению основных когнитивных способностей, показано, что в них в явном или неявном виде присутствует элемент интерпретации, который опосредует вписывание полученной информации в наличный опыт индивида. Это осуществляется, например, посредством использования данных, их реконструкции в процессе формирования образов или мышления, на уровне использования языка. Сделан вывод о том, что интерпретация и реализация когнитивных способностей взаимосвязаны и их успешная реализация способствует формированию стройной и непротиворечивой персональной картины мира. Тем самым исследование когнитивных способностей и их механизмов раскрывает новые аспекты проблемы интерпретации и понимания.

Ключевые слова: понимание, интерпретация, когнитивные способности, смысл, образ, информация, опыт, контекст, репрезентация, когнитивные схемы.
\end{abstract}

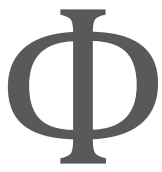

илософия рождается из природного устремления человека интересоваться собой и миром, в котором они живут. Одной из движущих сил человечества являются проблемы познания окружающего мира и себя самого, из которых вытекают прикладные и практические задачи, связанные с развитием общества, наук и технологий.

Познание представляет собой специфический предмет исследования. Мы можем рассматривать данный феномен с разных сторон. Он предстаёт как, например, познание индивидуальное, историческое (и культурное), и биолого-психологическое (рефлексы, инстинкты, мышление). Разнообразие проявления его форм позволяет изучать его различными дисциплинами, использовать различные подходы и точки зрения.

Как отмечает В.А. Лекторский, достижение современного познания состоит в утверждении коммуникационного подхода и выявлении в этой связи «фундаментальной важности факта производства и потребления знания для понимания са- мых разнообразных явлений» [5, с. 6]. В этой связи особое значение приобретает междисциплинарный подход, позволяющий использовать результаты конкретных дисциплин, имеющие значение для достижения целей исследования. Основной установкой и идеалом в деле познания, не зависимо от его предмета, будь то научное исследование в любой сфере, изучение конкретного предмета, события или осмысление социальных или обыденных явлений, является обогащение имеющегося знания и поиск истины.

Вопросы познания интересовали философов в самого момента зарождения данной дисциплины. В процессе развития философской мысли в связи с обширностью проблематики была выделена эпистемология в качестве теории познания. Перспективы развития данной области философского знания связаны с поиском теоретических основ осуществления процесса познания, призванных способствовать совершенствованию методов и способов понимания, нацеленных на «улучшение» человеческого познания. Нет принципов, кото- 
рые могли бы ограничить рост научного знания, поскольку становится очевидным зависимость наших когнитивных способностей от самых различных факторов, включающих эволюцию когнитивных процессов, и это открытый процесс.

Особый интерес в связи с тенденцией к междисциплинарности представляют дисциплины когнитивного комплекса, в центре внимания которых находятся традиционные для эпистемологии вопросы, ключевые из них касаются специфики процесса познания и организации знания. При этом междисциплинарный характер исследований обусловливает ценность философской методологии в выборе подхода, наиболее адекватного предмету исследования. В центре этих дисциплин остаются вопросы, касающиеся проблемы хранения, воспроизведения и передачи полученной человеком информации для адекватного восприятия и познания окружающего мира. А это нацеливает весь комплекс когнитивных исследований на выявление механизмов, обеспечивающих решение этого комплекса задач. Адекватное восприятие и познание мира понимается как наиболее объективное отражение происходящих явлений в их взаимосвязи с уже имеющимися у субъекта знаниями. Когнитивные способности человека сложились в результате длительного эволюционного (и когнитивного) развития вида, и под решающим влиянием социально-культурных факторов [6, с. 20-38]. Основные когнитивные способности, к которым относятся восприятие, внимание, память, мышление (пространственно-образное и логико-вербальное) и язык, сознание и самосознание обеспечивают возможность воспринимать, познавать и накапливать опыт, как индивидуальный, так коллективный. Стоит отметить, что имея общие истоки формирования и развития, когнитивные способности идут в общем единстве - один из когнитивных процессов затрагивает весь комплекс мыслительной и познавательной деятельности человека. Важно так же, что у каждого человека реализация когнитивных способностей, хотя будет осуществляться по общим механизмам и закономерностям, но и будет носить персональный характер.

Совокупный опыт человека представляет комплекс имеющихся знаний, представлений, навыков и умений. При этом характер персонального опыты индивида неоднородный. С одной стороны, он включает объективное и типичное знание, с другой стороны, опыт всегда представлен и структурирован как личный, в том смысле, что имеет и персональные проявления и уникальные черты. Указанные аспекты индивидуального опыта взаимосвязаны и в полной мере необходимы для эффективного и результативного восприятия, адекватного понимания и познания мира, что способствует формированию персонального образа мира. Стоит отметить, что образ мира в данном контексте понимается и используется не как понятие философское и культурологическое, а исходя из психологического и когнитивного подхода - т.е. как система субъективных представлений о мире, зафиксированных в виде моделей или репрезентаций реальности. Стоит отметить, что в процессе познавательной деятельности человек осознает свои действия как реально осуществляемые и направленные на освоение действительности во всём её многообразии, а это значит, что и действует он в зависимости от того, как он ее познает.

Познание, и сопутствующий ему выбор соответствующих методов для успешного осуществления данной деятельности представляет собой одну из ключевых способностей человека. Необходимым элементом и, одновременно, показателем эффективности познания, а так же его результативности, является понимание. Понимание сопряжено с мышлением, сознанием и иными когнитивными процессами, направленными на уяснение процессов, обеспечивающих и разъясняющих эти фундаментальные особенности жизнедеятельности человека.

Герменевтический подход оказывается эффективным методом понимания специфики организации знания, ориентированного на самые разные сферы деятельности людей, в особенности там, где ярко выражена потребность интерпретировать содержащуюся в ней символику. На современном этапе сфера исследований герменевтики связана с пониманием фундаментальных процессов человеческой жизни и существования как такового. Герменевтика объединяет в себе два фундаментальных направления: изучение понимания в связи с познанием (когнитивный аспект) и проблему интерпретации (методологический аспект) исследования.

Проблематика понимания остается в центре внимания философской герменевтики и рассматривается как фундаментальная философская проблема. В качестве основного метода для достижения понимания используется интерпретация. Истолкование, являясь одним из методов познания, как отмечает Э.Бетти «предназначено для решения эпистемологической проблемы понимания» [1, с. 21]. 
Расширение области применения герменевтики и усложнение её предмета позволяет выделить теорию интерпретации в качестве относительно самостоятельной области философского исследования, направленной на истолкование неявных, неизвестных ранее смыслов текстов, явлений и событий и построение методологии истолкования. Интерпретация понимается как когнитивная процедура установления содержания и значений истолковываемых понятий посредством их аппликации на исследуемую предметную область, одновременно, - это и результат данной процедуры. Т.е. в общем виде интерпретация представляет собой установление значения понятийных структур и состоит в наделении смыслами.

Теория интерпретации возникает из практических задач, целью которых является понимание. Однако круг проблем, объединенных термином «теория интерпретации» включает в себя поиск когнитивных оснований процесса понимания, изучение условий правильного понимания; она связана с проблемой постижения смысла интерпретируемого материала, с рассмотрением специфики процесса субъективного мышления во всем многообразии его творческих проявлений и т.д.

В настоящее время философия и, в частности, эпистемология использует проблематику когнитивных наук, включая их в проблемное поле философских исследований. Центральное место герменевтических исследований традиционно занимает соотношение понимания и интерпретации. В связи с этим закономерным является вопрос об участии и влиянии интерпретации в процессах, связанных с когнитивными способностями человека. Исследования данных феноменов проводятся, главным образом, в рамках философии и психологии и смежных с ними направлениях. Однако, несмотря на явные различия между результатами исследований конкретных дисциплин в деле изучения специфики процесса познания, можно сформулировать общий ход направленности философского и гуманитарного знания и этой точкой пересечения их проблематики является нацеленность на изучение сущности феноменов, участвующих в познании, деятельности и творчестве.

Изначально исследования когнитивных способностей нацелены на идентификацию и определение видов способностей, которые можно изучать, а так же анализ интерпретацию их сущности и основных свойств. В 1938 г. вышла работа Л.Л. Терстоуна «Первичные умственные способ- ности», в которой на основании тестирования студентов были проанализированы группы (или батареи) мер когнитивных способностей и специфика их выражения. Применяемые для этого тестовые задания, были предназначены для распознавания, диагностики и измерения только одной конкретной, особой когнитивной функции. В результате Л.Л. Терстоуном был выделен ряд факторов интеллекта, к которым применима четкая и отчетливая интерпретация:

- «S. Пространственный (Space): способность воспринимать и сравнивать пространственные паттерны;

- V.Вербальное понимание (Verbal comprehension): способность к определению значения слов и, более широко, к пониманию речи и оперированию вербальными отношениями;

- W. Беглость речи (Word fluency): способность быстро продуцировать слова в соответствии с определенными ограничениями в отношении их буквенного состава;

- N. Легкость числовых операций (Number facility): скорость и точность выполнения простых арифметических действий;

- $\quad$ I. Индукция (Induction): способность выводить правила, которым подчиняется конкретный набор стимулов;

- $\quad$ Р. Перцептивная скорость (Perceptual speed): скорость и точность обнаружения определенных визуальных стимулов в массиве материала или сравнения таких стимулов с какими-либо другими;

- D. Дедукция (Deduction): способность строить рассуждения от предпосылок к точным выводам;

- M. Механическая память (Rote memory): способность заучивать и воспроизводить по памяти произвольные связи между стимулами, такими как слова и числа» [9, с. 480-482].

По итогам исследования Л.Л. Терстоуном был сделан вывод, подтверждающий существование нескольких видов интеллекта вместо какого-то единого общего его вида. Однако позже он был сформулирован более мягко, и систематизирован в иерархический подход к когнитивным способностям и их исследованиям. Он представлен как иерархическая структура когнитивных способностей и предполагает положение о том, что природа когнитивных способностей неоднородна - их можно разделить на общие и специализированные.

Данный подход со временем получил различные формы, основные отличия которых, состояли 


\section{Психология и психотехника 1(76) • 2015}

в организации когнитивных способностей в соответствии с определенными факторами или особенностями их реализации.

Так, например, в британской психологии, опираясь на работу Ф. Вернона «Структура человеческих способностей», придерживаются позиции, что существует несколько уровней групповых факторов когнитивных способностей:

(1) основной (спирменовский фактор «g»), завершающий иерархическую организацию;

(2) второстепенные: фактор «v:ed» (вербальныйчисловой-образовательный) и фактор «k:m», («практический-механический-пространственный-физический»);

(3) и многочисленные специальные факторы, составляющие групповые (вербальный, числовой, пространственный и другие) [9, с. 480-482].

Другой вариант иерархического подхода представлен в частности Дж.П. Гилфордом, который был приверженцем идеи «структуры интеллекта» и предложил соответствующую модель (SI). Свою концепцию он изложил в работе «Природа человеческого интеллекта». В отличие от рассмотренной выше позиции британских коллег, он отвергал даже саму идею существования общего интеллекта (фактора «g»). По его мнению, каждую когнитивную способность можно классифицировать в соответствии с трёхуровневой типологизации, т.к. каждая из этих способностей, также как и связанный с ней фактор опосредованы определенным критерием. Дж.П. Гилфорд в качестве оснований для классификации типов когнитивных способностей выделяет:

- $\quad$ процесс (или когнитивную операцию). К этой группе он относит когницию (как процессы восприятия и обработки информации), память, оценку и процессы творческого мышления (конвергентное и дивергентное продуцирование);

- $\quad$ содержание, представленное различными его формами - образное, символическое, семантическое, поведенческое (связано с невербальным общением);

- $\quad$ результат (продукт), получаемый в результате обработки информации. Эта группа представлена различными элементами, классами, отношениями, системами, преобразованиями и импликациями.

В результате исследований Дж.П. Гилфорда, было развито и уточнено представление о факторах способностей. Хотя и не все исследователи со- гласились с этой моделью, она оказала значительное влияние на использование в качестве одного из ключевых методов изучения факторного анализа. Согласно такому подходу, посредством тестовых заданий возможно выявить и определить факторы когнитивных способностей, которые могут быть как единичными, так и составными, включающими несколько способностей.

Для современного этапа научного знания в области изучения когнитивных способностей характерно привлечение новейших теоретических разработок, технических средств и компьютеров. Всё это напрямую связано с междисциплинарным подходом и находит свое воплощение в программе конвергентных технологий.

Помимо общих исследований, посвященным природе и особенностям понимания когнитивных способностей, осуществляется работа по изучению их эволюции, особенностей организации и реализации при познании и деятельности человека. Эти исследования проходят, например, в рамках биологии, психологии, философии.

Как отмечает, И.П. Меркулов, «изначально человеческое познание имеет чувственную природу» [6, с. 38], т.е. опосредовано информацией, получаемой с помощью органов чувств, в связи с чем в качестве базовой когнитивной способности выступает восприятие. Первоначальным основанием для любого опыта является ощущение, возникающее в результате непосредственного воздействия, получения и обработки чувственных данных. Мир, в котором живет и действует человек, наполнен смыслами и информацией различного рода. В этой связи для эффективного получения необходимых данных, необходимо участие внимания и памяти, которые опосредуют выделение и обработку лишь той информации, которая необходима в каждом конкретном случае. Так, внимание направляет и управляет чувственным опытом, а память содержит в себе контекстуальные признаки, выражающиеся в определённого рода ожиданиях (например, смысловых или содержательных), и необходимы для его адекватного понимания.

Данные непосредственного чувственного, эмпирического опыта посредством восприятия предстают в сознании человека в виде различных перцептивных образов и их последовательности. Восприятие осуществляется в виде интерпретации полученных сенсорных данных, которые соотносятся с уже имеющимся у субъекта знанием и опытом. Именно на этом этапе происходит наделение 
смыслом элементарных, схваченных ощущений на основании ассоциаций и соотношения с прошлым опытом. Более того, сама интерпретация предполагает участие восприятия, на уровне которого происходит первоначальное «считывание», расшифровка смыслов и определение их значений (буквальных, символических, мистических, иносказательных и т.д.). Тем самым создаются внутренние основы для формирования личностного знания. Оно не ограничивается исключительно личностным опытом (индивидуально полученным смыслом), но опосредовано внутренними интенциями, которые приобретают социальный характер, выраженный посредством производства значений и смыслов.

Таким образом, процесс восприятия зависит не только от исходной сенсорной информации, но от наличного знания, появляющихся мнений, суждений и гипотез. Учитывая данный аспект, можно отметить, что восприятие взаимно опосредует и имеет отношение к более сложным когнитивным способностям. На это указывает и И.П. Меркулов: «Эффективность восприятия базируется не только на своих собственных когнитивных программax, но и на их тесной интеграции и кооперации с параллельно функционирующими программами, управляющими распознаванием перцептивных образов, работой кратковременной и долговременной памяти, внимания, мышления и т.д., без которых немыслимо научение и более адаптивное поведение» [6, с. 65]. Результаты, полученные при восприятии, создают основу, своеобразную «базу данных» для их совместной реализации и развития. Для успешного осуществления интерпретации воспринимаемых данных необходимо достижения определенного уровня абстрагирования, для возможности наилучшего соотнесения полученной информации с уже имеющимися знаниями и структур или систем для их понимания.

Восприятие может происходить на уровне не только непосредственно получаемой сенсорной информации, но, и результатов познавательной и мыслительной деятельности. Используя ресурсы внимания, вызывая в процессе интерпретации в памяти определенные воспоминания в форме ощущений, образов, ассоциаций восприятие происходит уже не автоматически, а требует дополнительной работы, например, по сопоставлению образа с воспринимаемым объектом, а это осуществляется при помощи дополнительной работы сознания. Оно отвечает за контроль и понимание всех окру- жающих явлений, будь то ощущения, мысли, образы или воспоминания. В связи с обилием и многообразием данных и смыслов, содержащихся в мире, сознание предполагает возможность его избирательной работы, т.е. концентрации лишь на необходимом субъекту аспекте объекта, деятельности или даже реальности.

Р. Солсо систематизирует и выделяет следующие функции сознания:

1. определение значения информации, где наиболее заметно участие интерпретации;

2. адаптация и научение, способствующие встраиванию нового знания в уже имеющуюся систему;

3. установление приоритетов информации, затрагивающие механизмы внимания и обращения к необходимым участкам памяти;

4. контроль действий, как физических, так и умственных, который обеспечивается с помощью постановки целей и формулирования мотивации;

5. принятие решений, особенно требующих времени или раздумий;

6. редактирование ошибок, возможных или возникающих в процессе деятельности;

7. самоконтроль и рефлексия;

8. управление внутренней организацией и гибкостью, которые обеспечивают как эффективную ориентацию и действие в рамках устоявшейся системы знания или принятых традиций, так и способствуют поиску нетривиальных решений и появлению открытий [10, с. 130-131].

Понимание, осуществляемое на уровне сознательного восприятия можно характеризовать как творческий процесс, направленный на воссоздание содержащихся смыслов. Этот аспект проблемы истолкования представлен в работах И.Т. Касавина, который пишет: «использование смыслов невозможно вне «пропускания их через голову», вне сознательного промысливания, осмысления при построении той же коммуникации, деятельности или культурных артефактов. Смысл артикулируется человеком в речи, актах именования, интерпретации, рассуждения и встраивается в те явления, которые без таких процедур смыслом не обладают» $[4$, с. 20]. Тем самым постоянную деятельность по интерпретации смыслов, которая сопровождает жизнедеятельность и формы общения человека, следует характеризовать как естественную необходимость, выработанную в процессе когнитивной эволюции и истории человека.

Процессы мышления, в которых особенно заметна деятельность по интерпретации, связана с 


\section{Психология и психотехника 1(76) • 2015}

их совместным участием в формировании мысленных образов, которые определяются когнитивными психологами как репрезентация «в уме отсутствующего объекта или события» $[10$, с. 328]. Это может быть как образ отдельного предмета или класса предметов, личное понимание какого-либо явления или события, представление о конкретном человеке. Кроме того, при восприятии и последующем запоминании, возможны различные варианты образа одного и того же объекта, например, он может:

1. ассоциироваться с его эталонами, прототипами или составляющими его частями и компонентами;

2. вызывать определенный образ;

3. мыслиться в контексте большей системы образов.

Эти аспекты восприятия образа не исключают друг друга, но, наоборот, при совместном использовании способствуют наилучшей интерпретации и дальнейшей работе с полученными результатами. Другими словами, процессы репрезентации применимы к любым типам знаний и опыта, которые сопровождают человека.

Репрезентация понимается как значимая, символически представленная информация, в её взаимосвязи с уже имеющимися знаниями, и как структуры знаний определенной социальной группы. В широком смысле репрезентации являются теоретическими средствами, которые помогают делать заключения относительно общих значений и знаний. Несмотря на то, что основной целью конструирования репрезентаций является понимание, объяснение и предсказание действительности, данные структуры не прочны и подвижны. При изменении ситуации или её элемента, меняется и целостное восприятие явления, что приводит к появлению новых когнитивных схем и моделей. Формирование последних субъективно и обусловлено личным опытом, стереотипами, мнениями, оценками и эмоциями. Каждая репрезентация порождает уникальные ожидания и мысленные образы, способствующие встраиванию человека в социальную реальность, в пределах которой он живет и действует. Созданный на основании отдельных репрезентаций образ мира формируется затем в систему или когнитивную карту. Её можно определить как субъективную мысленную картину, в которой расположены отдельные воспринимаемые предметы. Для понимания и интерпретации когнитивной карты и входящих в неё образов, используются такие операции (методологические шаги), как:
1) выделение значимых, существенных признаков;

2) расположение их в необходимую последовательность;

3) преобразование полученных образов в новое знание, оформляемое в вербальной или не вербальной форме.

Значение и ценность когнитивных репрезентаций и когнитивных карт заключается в том, что первые позволяют моделировать и предвосхищать ход конкретного события, на которое направлено «понимающее» восприятие события, а вторые способствуют адекватной ориентации человека в окружающем мире.

Для эффективной ориентации в мире, необходимо учитывать соотношение элементов личного, интенционального и социального знания, что подразумевает деятельность по его интерпретации. Это происходит во всех случаях, касающихся получения знания и личного опыта. Причем личный опыт понимания, или так называемые когнитивные практики основываются на предпонимании, которое можно рассматривать и как когнитивную деятельность и как феномен процесса понимания.

Особо стоит выделить в этой связи значение и влияние акта предпонимания, основанием которого является наличие предварительного знания о предмете или ситуации, полученного в результате субъективного внутреннего опыта. «Предпонимание, - пишет Е.Н. Шульга, - выступает одновременно как категория описания, выяснения и одновременно как элемент воссоздания смысла» [12, с. 33]. Это значит, что актом предпонимания в интерпретации как деятельности обеспечивается возможность сопоставления индивидуальных подходов, взглядов и даже контекстов, что, в конечном итоге, делает понимание одного человека другим доступным, приоткрывая скрытые смыслы.

Специфика феномена предпонимания раскрывает себя благодаря участию социального начала, которое имеет место в любой человеческой деятельности, в том числе и в познании. Эта специфика «социальности» выражается в наличии у человека установок, стереотипов понимания, позволяющих соотнести собственный, индивидуальный опыт (предпонимание, личностное знание) и уже имеющиеся смыслы, касающиеся интерпретации явлений. И эта когнитивная практика опирается на наличное знание, которое человек интерпретирует в нужном контексте. При этом не следует забывать, что сознание человека, его индивидуальность и личность формируются 
в пределах определенной культуры, внутри языка и традиции, в тех конкретных условиях становления и реализации норм, знаний, стереотипов, которые позволяют определять и понимать социальные, этические и религиозные категории и установки. Более того, использование культурных компонентов для конструирования и определения моделей и образцов значений и способов репрезентации знаний является необходимым аспектом, обеспечивающим адекватное конструирование и познание мира.

Получаемые ментальные модели и когнитивные схемы хранятся в памяти, и обладают способностью к обновлению, однако, изменить уже устоявшиеся на когнитивном и ментальном уровнях фреймы оказывается сложно. Системы представлений, в таком случае, нуждаются в переформулировке и замене, что способствует изменению ориентиров познания и понимания. Здесь интерпретация нацелена на понимание тех конкретных аспектов мировосприятия, которые опосредуют организацию знания (внутри частной картины мира).

Как уже отмечалось, ресурсы памяти присутствуют и используются при реализации всех когнитивных процессов человека. Более того, известно, что умение быстро запоминать необходимую информацию, а так же «архивировать» данные, правильно систематизировать и использовать их во многом опосредует успешность и эффективность человеческих действий, поступков и даже межличностных отношений. Это связано и с тем, что необходимые и существенные связи имеют повторяющийся и закономерный характер.

Известны люди с врожденной способностью к быстрому и качественному запоминанию (текстов, цифр, лиц, образов или всей полученной информации). Кроме того, эти способности можно и развивать. Так, в последнее время, весьма распространено такое явление, как мнемоника. Она представляет собой особый способ организации и кодирования воспринимаемых данных и знаний для их наилучшего запоминания и последующего использования. Чаще всего, для этого используются приёмы визуализации, отвлечения, ассоциации, вызывающие соответствующие мысленные образы, привлечение ключевых слов, объединение образов в группы или схемы, а так же образование аббревиатур и сокращений. При выборе наиболее подходящего мнемонического приёма и его эффективного применения большое значение отводится интерпретации. Поскольку она опосредует когнитивные механизмы, участвующие при запоминании, си- стематизации и применении полученных данных. Правильно организованные и глубокие знания представляются наиболее доступными, содержательными, эффективными и функциональными, что позволяет определить их как предпосылку и показатель результативности, квалификации и компетенции человека. Так же стоит отметить, что сохранение памяти и воспоминаний обеспечивают единство личности в течение жизни.

Мышление сопровождает всю сознательную деятельность человека и понимается как процесс, направленный на решение проблем и представленный в виде последовательного перехода от проблемы и её условий к получению решения, конкретного результата. Другими словами, основными элементами мышления являются мысленные репрезентации и оперирование с ними. Проблемный характер мышления опосредует его обязательную направленость на конкретную проблему или объект и предполагает активную конструктивную деятельность по делению исходной информации на составляющие, их анализ, переструктурирование и дополнение.

Мышление сопровождает процесс формирования понятий, связано с логикой и здравым смыслом. При этом, как отмечает И.П. Меркулов, именно возникновение мышления способствовало формированию способности к пониманию [6, с. 78]. В исследуемом нами контексте понимание может рассматриваться как элемент когнитивной творческой деятельности человеческого мышления и его фундаментальные свойства, так и конечный результат процесса интерпретации в его эпистемологической и методологической части.

Исследователи процессов мышления выделяют три его типа: знаково-символическое, логиковербальное и образное. Они взаимно дополняют друг друга, хотя и имеют свои особенности проявлений, в том смысле, что оперируют с определенным классом объектов. Эволюция логико-вербального и образного мышления явилось движущим фактором для формирования и развития коммуникативных навыков и творческих аспектов познания и деятельности человека.

Язык - представляет собой первичную, наиболее естественную и общедоступную репрезентацию мира, средство коммуникации и орудие мышления, форму деятельности и форму отражения культуры, задает исходные схемы ориентации человека в мире. Более того, как пишет И.А. Михайлов, немецкий философ Г. Липпс убежден, что «вопрос о «человеке», с одной стороны, и вопрошание о «речи», 
«языке» - с другой - оказываются, в конечном счете, вопросами об одном и том же. Речь, язык <...> служат ключом к пониманию тайны человеческого бытия, его экзистенциальности» [7, с. 131-132].

В языке и речи изначально заложено сходство с миром знаков в том смысле, что оно формируется с помощью норм, правил, знаков, значений. Символизм мира включен в человеческие действия в той мере, в какой то или иное действие является частью определенной системы, формирующей контекст понимания мира, без знания которой невозможно понять смысл этого действия. При этом «понимание мира» включается в процесс коммуникации, предполагает открытость и постоянную готовность к изменению любых исходных позиций, определяющих контекст понимания.

При истолковании здесь учитываются социально-психологические моменты: анализируется сама ситуация в целом (восприятие ситуации как «текста»), интерпретируется аргументация, оценивается речь, её стиль и характер, наряду с невербальными элементами коммуникации (например, подтекст, мотивы). Результат общения мы можем характеризовать как способ передачи информации, трансляции знания, сведений, эмоций, наконец, мы оказываемся в состоянии «считывать» скрытый подтекст, который содержит в себе текст речи участников коммуникации.

Воображение является, одновременно, и одной из когнитивных способностей человека и ключевым способом реализации его творческой активности. Оно предполагает участие всех высших когнитивных способностей и понимается как процесс деятельности (мыслительной или психической) по созданию и преобразованию образов или ситуаций, опирающимся на уже имеющееся, приобретенное ранее знание. Данный процесс выражается, как способность производить мысленные преобразования над существующими предметами и формировать на их основе образы, которые, будучи отличными от оригиналов, тем не менее, воспринимаются как адекватные им. Все преобразования в процессе данной деятельности происходят в сознании человека, реальным может быть лишь её результат в условиях его реализации в виде продуктов творческой деятельности, художественной или научной.

В качестве характерных черт выделяется познавательный аспект воображения, состоящий в использовании и преобразовании чувственных данных, формировании на их основе общих поня- тий и мысленных образов, а так же, способности соотнесения последних друг с другом. Таким образом, можно сказать, что воображение выступает своеобразным посредником между чувственным, эмпирическим познанием и абстрактным теоретическим мышлением.

Включая в качестве обязательного компонента личный опыт, воображение предстает как субъективный феномен. Этот аспект особенно заметен в процессе творчества, где наиболее ярко проявляется взаимосвязь познания и воображения. Так, например, С.С. Гусев, обращая внимание на субъективный характер процесса познания, рассматривает текст как субъективную реальность, в которой раскрывается мыслительная творческая активность людей, реализующаяся в создании и порождении множества образов, благодаря которым сложная система человеческих действий предстаёт как упорядоченный «мир сам по себе». Появление нового в познании опосредовано воображением и интерпретацией, где интерпретация раскрывается как выявление субъективных намерений познающего субъекта. Важно при этом, что это мир идеальных объектовобразов, но «человек, - как пишет С.С. Гусев, - одновременно обитает в нескольких “мирах". Мир предметных, телесно выраженных форм и мир форм “идеальных", не связанных с какими-то конкретно выраженными пространственными рамками, - взаимодействуют сложным образом и в равной степени регулируют весь комплекс жизнедеятельности людей» [3, с. 59].

При этом важно, что воображение является специфической человеческой способностью, опосредованной не столько органическими потребностями, сколько общечеловеческими и культурными факторами: «На животное производят впечатление только непосредственно для жизни необходимые лучи солнца, на человека - равнодушное сияние отдаленнейших звезд. Только человеку доступны чистые, интеллектуальные, бескорыстные радости и аффекты; только человеческие глаза знают духовные пиршества» $[11$, с. 24]. Благодаря социальной обусловленности, воображение является одним из условий взаимопонимания в обществе, обеспечивая возможность правильного понимания и истолкования.

С помощью воображения осуществляется репрезентация чувственной информации, и их последующая систематизация, структурирование и согласование с имеющимся знанием и опытом, а также формирование на их основе новых образов. 
Адекватное познание и деятельность человека предполагают участие воображения, поскольку именно оно помогает отвлечься, отстраниться от непосредственных чувственных данных и впечатлений, которые формируют образ действительности, и от привычного восприятия реальности. Такое участие воображения осуществляется при помощи активной деятельности сознания, усилий воли и рациональных действий человека [см.: 8].

В качестве базовой единицы воображения выделяется мысленный образ, который, как уже отмечалось выше, является результатом интеллектуальной активности индивида. Одним из способов формирования мысленных образов является синестезия, определяемая как механизм мультисенсорной обработки и понимаемая как «состояние, в котором ощущения одной модальности (например, зрение) переживаются в другой модальности (например, слух)» [10, с. 350]. Специфическим при этом является не только способность перенесения ощущений одного вида, на другой, но и их одновременное переживание в нескольких модальностях (например, данные о сопоставлении цвета и звука, полученные в ходе исследований Л. Маркса (Marks, 1974)). Для продуктивного восприятия подобных образов большое значение имеет интерпретация, как процедура по соотнесению разных видов восприятия, порожденных ими смыслов и способность к ассоциированию получаемых данных. Результаты когнитивной деятельности (объекты, эмоции, абстрактные понятия) оформляются в виде звуково-зрительных образов сознания, наделенных определенным смыслом и содержащих символически или знаково выраженную связь с воспринимаемым предметом. Индивидуальная способность к гармонизации различных модальностей восприятия зависит от уровня развития психических и интеллектуальных качеств человека. Процесс интерпретации в этом контексте является объединяющим фактором для многообразных способов, формирующих образы и представления, репродуктивных актов деятельности.

Итак, сохраняя общие черты оригинального объекта, воображение позволяет создавать новые образы и формировать новое знание, что говорит не только о воспроизводящей, но и творческой направленности данной способности. Творческое воображение создает индивидуальные вариации всеобщего, сформулированного знания и способствует созданию новых, но, тем не менее, основанных на нём образцов. Но этот процесс не является лишь воплощением индивидуальности или выражением творческих наклонностей отдельного познающего или деятельного субъекта, более того, что любые гипотетические отклонения здесь не являются произвольным воплощением его «игры разума» и воображения. Напротив, создаваемый образ, в определенной степени зависим от общих идей и тенденций развития культуры, общества и науки. Это может быть как следование принятым направлениям, так и, наоборот, стремление к эпатажу. Так, например, Л. Бунюэль пишет, что «истинная цель сюрреализма заключалась не в том, чтобы сформировать новое направление в литературе, живописи и даже философии, а в том, чтобы взорвать общество, изменить жизнь» [2, с. 51]. Однако, как известно, реализовывали представители указанного течения именно с помощью художественных образов, воплощаемых в картинах, литературных произведениях, фильмах, различных инсталляциях и инсценировках. Поэтому мы вправе утверждать, что органическое соединение свободы творчества (воображения) и использование социальной и культурной традиции способствуют наиболее продуктивной деятельности.

В целом деятельность интеллекта можно квалифицировать как определенного рода «программу деятельности, поведения и общения». Она включает в себя оценку различного рода знания, учитывает навыки и их многообразие, повседневный опыт общения, включает в себя этические нормы и предписания, образцы поведения и ритуалы, наконец, идеалы, идеи, верования, эстетические ценности. Именно на этом уровне происходит включение интерпретации в распознавании смысла коммуникативных действий. Такая «программа деятельности, поведения и общения» формируется на основании использования совокупного социального опыта и исторического контекста (традиции, того, что составляет культуру поведения и общения). Тем самым концепция философии интерпретации обогащается за счёт привлечения деятельностных характеристик, восходящих к продуктивной и репродуктивной деятельности сознания, направленной на производство и воссоздание смыслов, понимаемых и рассматриваемых в контексте ценностных, культурных смыслов (Имеются в виду культурные смыслы, которые продуцирует сознание человека, в отличие от смыслов культуры, понимаемых как язык, артефакты, произведения искусства и т.д.).

Таким образом, рассматривая специфику когнитивного аспекта интерпретации, следует ска- 


\section{Психология и психотехника 1(76) • 2015}

зать, что процесс познания представляет собой не только фиксацию в сознании связей, отношений, явлений, процессов и закономерностей, существующих в окружающем мире, но предполагает реконструкцию, т.е. их интерпретацию. Эта интеллектуальная деятельность осуществляется на основе когнитивных репрезентаций, благодаря которым происходит создание определенного образа мира. На этом когнитивном этапе формирования частной картины мира, или образа мира, интерпретации придаётся особое значение. Интерпретация направлена на осмысление и понимание действительности (её событий, явлений, фактов) и по сути дела представляет собой непрерывный процесс создания когнитивных репрезентаций, которые, в конечном итоге, оформляются в непротиворечивую картину мира (О репрезентативном характере субъективной модели мира пишет, в частности, O.E. Баксанский [см.: 14]). Познание, понимание и интерпретация способствуют правильному пониманию смыслов, заключенных в событиях, действиях и поступках людей, в предметах, объектах окружающего мире и его проявлениях.

Понимание, будучи связанным с постижением специфики внутренних когнитивных процессов субъективного свойства, выводит проблематику интерпретации на фундаментальный уровень исследования, рождая потребность в поиске новых аргументов в пользу относительно самостоятельного статуса теории интерпретации.

\section{Список литературы:}

1. Бетти Э. Герменевтика как общая методология наук о духе. М.: Канон+, 2011. 144 с.

2. Бунюэль Л. Мой последний вздох. М.: Книга по Требованию, 2012. 128 с.

3. Гусев С.С. Метафизика текста. Коммуникативная логика. СПб.: ИЦ «Гуманитарная академия», 2008. 352 с.

4. Касавин И.Т. Коммуникация и творчество // Философия науки. Выпуск 17. Эпистемологический анализ коммуникации. М.: ИФ РАН, 2012. С. 7-23.

5. Лекторский В.А. Эпистемология классическая и неклассическая. М.: Эдиториал, 2001. 256 с.

6. Меркулов И.П. Когнитивные способности. М.: ИФ РАН, 2005. 182 с.

7. Михайлов И.А. «Герменевтическая логика» Ганса Липпса // Точки. Ежеквартальный католический журнал, посвященный проблемам религии, культуры и общества. 3-4/2/2001. С. 125-145.

8. Пилюгина М.А. Воображение как способ познавательной деятельности // Проблема воображения в эволюционной эпистемологии. М.: ИФ РАН, 2013. С. 195-205.

9. Психологическая энциклопедия. 2-е изд. / Под ред. Р. Корсини, А. Ауэрбаха. СПб.: Питер, 2006. 1096 с.

10. Солсо Р. Когнитивная психология. 6-е изд. СПб.: Питер. 2006. 589 с.

11. Людвиг Фейербах. Сущность христианства. М.: Мысль, 1965. 416 с.

12. Шульга Е.Н. Проблематика предпонимания в герменевтике, феноменологии и социологии. М.: ИФ РАН, 2004.173 с.

13. Баксанский О.Е. Когнитивные репрезентации картины мира: от здравого смысла к научному познанию // Психология и психотехника. 2014. № 3. С. 266-274. (DOI: 10.7256/2070-8955.2014.3.11474).

14. Баксанский О.Е. Когнитивные репрезентации: обыденные, социальные, научные. М.: Либроком, 2009.224 с.

\section{References (transliteration):}

1. Betti E. Germenevtika kak obshchaya metodologiya nauk o dukhe. M.: Kanon+, 2011.144 s.

2. Bunyuel' L. Moi poslednii vzdokh. M.: Kniga po Trebovaniyu, 2012.128 s.

3. Gusev S.S. Metafizika teksta. Kommunikativnaya logika. SPb.: ITs «Gumanitarnaya akademiya», 2008. $352 \mathrm{~s}$.

4. Kasavin I.T. Kommunikatsiya i tvorchestvo // Filosofiya nauki. Vypusk 17. Epistemologicheskii analiz kommunikatsii. M.: IF RAN, 2012. S. 7-23.

5. Lektorskii V.A. Epistemologiya klassicheskaya i neklassicheskaya. M.: Editorial, 2001. $256 \mathrm{~s}$.

6. Merkulov I.P. Kognitivnye sposobnosti. M.: IF RAN, 2005. 182 s.

7. Mikhailov I.A. «Germenevticheskaya logika» Gansa Lippsa // Tochki. Ezhekvartal'nyi katolicheskii zhurnal, posvyashchennyi problemam religii, kul'tury i obshchestva. 3-4/2/2001. S. 125-145.

8. Pilyugina M.A. Voobrazhenie kak sposob poznavatel'noi deyatel'nosti // Problema voobrazheniya v evolyutsionnoi epistemologii. M.: IF RAN, 2013. S. 195-205.

9. $\quad$ Psikhologicheskaya entsiklopediya. 2-e izd. / Pod red. R. Korsini, A. Auerbakha. SPb.: Piter, 2006. 1096 s.

10. Solso R. Kognitivnaya psikhologiya. 6-e izd. SPb.: Piter. 2006. 589 s.

11. Lyudvig Feierbakh. Sushchnost' khristianstva. M.: Mysl', 1965. 416 s.

12. Shul'ga E.N. Problematika predponimaniya v germenevtike, fenomenologii i sotsiologii. M.: IF RAN, 2004.173 s.

13. Baksanskii O.E. Kognitivnye reprezentatsii kartiny mira: ot zdravogo smysla k nauchnomu poznaniyu // Psikhologiya i psikhotekhnika. 2014. № 3. S. 266-274. (DOI: 10.7256/2070-8955.2014.3.11474).

14. Baksanskii O.E. Kognitivnye reprezentatsii: obydennye, sotsial`nye, nauchnye. M.: Liberkom, 2009. 224 s. 